\title{
Observaciones en torno al área dialectal leonesa: sobre viejos límites eclesiásticos y lingüísticos*
}

\author{
Observations about the dialectal area of Leonese: On some old \\ ecclesiastical and linguistic boundaries
}

\author{
Borja Alonso Pascua \\ Universidad de Salamanca \\ borjalonso@usal.es \\ ORCID iD: https://orcid.org/0000-0003-0503-0359
}

RESUMEN: Este artículo examina una propuesta según la cual la expansión del dialecto leonés y de sus variedades internas constituye un reflejo aproximado de las antiguas fronteras diocesanas de la península ibérica. El objetivo es observar en qué medida las isoglosas lingüísticas se ajustan con mayor fidelidad a las fronteras eclesiásticas que a las civiles, ya sean las del antiguo reino de León o las de la actual división provincial. El examen comparado de ambos límites revela, en efecto, correspondencias que apuntan al papel determinante de las viejas diócesis en la configuración linguiística del territorio.

Palabras clave: dialectología española, leonés, dominio lingüístico, frontera lingüística, isoglosa, límite eclesiástico, diócesis.

ABSTRACT: This paper tests a proposal according to which the expansion of the Leonese dialect and its internal varieties approximately abides by the old diocesan boundaries of the Iberian peninsula. The aim is to examine to what extent linguistic isoglosses more accurately mirror the ecclesiastical boundaries as opposed to the civil ones, whether it be those of the old Kingdom of Leon or of the contemporary provincial division. The compared exam of both boundaries reveals, indeed, correspondences pointing to the key role of the old dioceses in the configuration of the Iberian linguistic landscape.

Keywords: Spanish dialectology, Leonese, linguistic domain, linguistic boundary, isogloss, ecclesiastical boundary, diocese.

* Este trabajo cuenta con el respaldo económico del proyecto FFI-2017-82249-P (Ministerio de Economía y Competitividad), que financia la actividad del GIR "Gramática Descriptiva e Historiografía de la Gramática Española" (UIC 046 de la Junta de Castilla y León), y de la ayuda FPU17/05702 (Ministerio de Ciencia, Innovación y Universidades). Quedo agradecido a los dos evaluadores anónimos por sus acertados comentarios y sugerencias de mejora; los errores que persistan son responsabilidad mía. 
Las variedades leonesas al sur de la cordillera cantábrica se extienden a lo largo de un área comprendida entre la orla montañosa del norte de León, donde el dialecto goza todavía de cierta vitalidad, y las sierras meridionales de Salamanca, en las que hoy ya solo pueden rastrearse meras huellas testimoniales de un pasado lingüístico leonés. Puntualmente, estas variedades se prolongan, con carácter residual y en concomitancia con rasgos sureños, por las comarcas de Las Hurdes, Vega del Alagón y Tierra de Alcántara, donde se funden con las hablas extremeñas. Por el oeste, el macizo galaico marca la transición hacia el gallego, mientras que, por el este, la ribera del Esla y la Ruta de la Plata establecen el límite, cada vez más diluido, con las hablas propiamente castellanas. En un intento de explicar la particular distribución de estas variedades, se propone adoptar aquí una perspectiva en la que las fronteras externas e internas del espacio dialectal se enfocan desde la horma no de los límites geográficos tradicionales, sino de las viejas fronteras eclesiásticas (Menéndez Pidal, 1906, 1908 y 1916; Morf, 1911; Tallgren, 1913; Zamora Vicente, 1982 y 1987; Morala, 2011).

La mayor parte de esta superficie, repartida en lo civil entre las provincias de León, Zamora y Salamanca, se hallaba hasta fechas cercanas administrada en lo espiritual por las diócesis de Oviedo, León, Santiago de Compostela, Astorga, Zamora, Salamanca y Ciudad Rodrigo. Varias feligresías del sur del dominio dialectal eran jurisdicción de los obispos de Coria, Plasencia y Ávila, diócesis esta última que también regía la franja oriental de la provincia de Salamanca. Por el noroeste, la diócesis de Lugo gobernaba una pequeña demarcación fronteriza con Galicia en el oeste de El Bierzo, mientras que la de Orense hacía lo propio con las parroquias sanabresas occidentales. El mapa resultante, al que hay que sumar ciertos enclaves diseminados de norte a sur por todo el territorio del viejo reino, muestra un complejo entramado de fronteras que apenas experimentó cambios significativos hasta los años 50 del pasado siglo, cuando la Iglesia española conoce una reestructuración sin precedentes que dejará una nueva carta eclesiástica a comienzos de 1960. El interés de estudiar el papel de estas divisiones sobre la segmentación dialectal del territorio es evidente si se tiene en cuenta, en primer lugar, la larga vida de estos límites, con holgada diferencia más antiguos que los de las modernas provincias decimonónicas a las que tradicionalmente han recurrido con discutible acierto las descripciones dialectológicas. En segundo, la relevancia de la entidad episcopal para la vida espiritual y temporal del país favoreció la longevidad secular de estas fronteras, que, a diferencia de los históricos confines medievales, permanecieron casi inalteradas con el correr de los años, oficiando, según el caso, de verdaderos límites linguiísticos.

Con el fin de evaluar el poder explicativo de esta hipótesis, que, si bien no es nueva en cuanto a su formulación, sí lo es en cuanto a su aplicación detallada al dominio leonés, en primer lugar se presentará un breve esbozo del noroeste peninsular como complejo dialectal con especial atención a la ausencia de correspondencia entre límites linguiísticos y políticos. En segundo, se fijará el área 
de influencia de las variedades leonesas atendiendo a sus fronteras tanto externas como internas para, a continuación, exponer la citada propuesta y analizarla a la luz de la cartografía lingüística vigente y del antiguo mapa eclesiástico peninsular. Por último, se sintetizarán las conclusiones del análisis y se perfilarán las líneas de guía para su aplicación a otros dominios dialectales.

\section{EL NOROCCIDENTE PENINSULAR COMO COMPLEJO DIALECTAL}

A la hora de parcelar una zona de influencia dialectal, los manuales clásicos de dialectología peninsular (García de Diego, 1946; Zamora Vicente, 1960; Alvar, 1996) han echado mano con sistemática asiduidad de las divisiones históricas y provinciales. Así, cuando se menciona el área dialectal del leonés —o del castellano con rasgos leoneses - el lingüista parece acudir presuroso a trazar un campo de acción que inexcusablemente comprenderá las provincias de León, Zamora, Salamanca y, en el mejor de los casos, el norte de la actual Cáceres y la mitad noroeste de Cantabria. Desde Menéndez Pidal (1906) son sobrados, en efecto, los argumentos para postular una unidad lingüística de estos territorios cimentada en la amplitud y vitalidad de determinadas soluciones fonéticas, morfosintácticas y léxicas. De igual manera es sabido, sin embargo, que la realidad lingüística poco obedece a los límites políticos, de forma que ni los rasgos leoneses se manifiestan solo dentro de las demarcaciones provinciales del viejo reino, ni todos los territorios que estas engloban pueden adscribirse hoy a un dominio dialectal leonés. La unidad lingüística de las provincias occidentales, que no pretende aquí ponerse en duda, no ha de concebirse a modo de territorio blindado y, por consiguiente, ajeno al contacto con los dialectos circundantes. Nada más lejos, por otra parte, de los hechos lingüísticos.

Es cierto que los métodos de la geografía lingüística, que en el caso del área analizada dieron provechosos frutos con la publicación del Atlas Lingüístico de Castilla y León $(A L C y L)$, han corroborado por un lado la homogeneidad dialectal de las provincias occidentales, pero también lo es que, por otro, han revelado un complejo panorama de isoglosas que se entrecruzan, se ensanchan y se encojen zafándose a su gusto de la rigidez de los límites provinciales. Estas demarcaciones no explican por sí solas —como tampoco parece hacerlo la trillada división medieval entre León y Castilla- la distribución en apariencia veleidosa de las isoglosas externas e internas que surcan de norte a sur y de este a oeste el dominio dialectal (Morala, 2011: 104; Sánchez Jiménez, 2016: 69), en especial en los territorios más septentrionales en los que el latín evolucionó in situ sin el concurso de los procesos niveladores verificados en torno al Duero, al sur del cual vienen precisamente a morir la mayoría de los fenómenos dialectales leoneses (Fernández-Ordóñez, 2012; Echenique y Sánchez, 2005: 355, 366). Definir, pues, las agrupaciones dialectales 
de la submeseta norte exige delinear contornos distintos de los tradicionalmente plasmados en los mapas político-históricos.

Por otro lado, tanto León como Zamora y Salamanca han conocido y conocen la irrupción de rasgos propios de otros dominios dialectales, ya sea el netamente castellano trueque de clíticos que permea por el este de las tres provincias o la ausencia de diptongación de Ě y Ǒ en la Alta Sanabria y la franja oeste de León, de clara filiación gallega. Como sugieren Borrego (1999) y Morala (2002), basta, por otro lado, con hojear unas pocas láminas del $A L C y L$ para constatar cómo la provincia de Salamanca se integra en unas ocasiones en un bloque occidental bien definido con Zamora y León (cfr. mapa 440), mientras que en otras se alía con Ávila para formar un corredor lingüístico meridional (cfr. mapas 627 y 789). Y lo mismo sucede en el noreste del dominio, donde León se asocia con Palencia y llega incluso a compartir rasgos dialectales con la franja norte de Valladolid (cfr. mapa 450). Desde un punto de vista interno, esa uniformidad se ve igualmente alterada por una fuerte variación en lo que afecta a las soluciones dialectales vivas en las diferentes comarcas del dominio. Ya Menéndez Pidal (1906: 28 y ss.), en la obra fundacional de los estudios leoneses, había esbozado una primera propuesta de fragmentación interna que sería reelaborada décadas después con acreditado éxito por Borrego (1996) (vid. infra 2.2.). Tal diversidad había sido comúnmente achacada a la naturaleza caprichosa e indomeñable de una lengua que vive en contacto con un sistema en pleno proceso de expansión como el conocido por el castellano en época medieval. Sabemos, ahora bien, que, en su avanzar por el centro peninsular, la cuña invertida no triunfó en todas las zonas del dominio occidental, y en las que lo hizo no consiguió desbancar con igual fuerza al viejo dialecto, que imprimió también su huella en las variedades centrales (Fernández-Ordóñez, 2012: 54).

Así las cosas, la cuestión que se plantea es la siguiente: si ciertamente los límites político-históricos, ya sean antiguos o modernos, no alcanzan a explicar la compleja distribución de los dominios lingüísticos peninsulares, ¿caben otras circunstancias, más allá de los indiscutibles contactos humanos (Penny, 2003), hacia las que volver la mirada en la interpretación de los mapas dialectales? Al debate de esta cuestión y a su análisis en el ámbito dialectal del leonés se dedicarán los epígrafes siguientes.

\section{LOS CONTORNOS LINGÜÍSTICOS DEL ESPACIO DIALECTAL LEONÉS}

\subsection{Las fronteras externas}

Viene siendo lugar común, en las obras panorámicas sobre el leonés y las variedades castellanas que presentan vestigios leoneses, el identificar su área de expansión con los territorios abrazados por los límites del histórico reino de León. 
Cuando Menéndez Pidal (1906) publica El dialecto leonés, la escasez de datos disponibles sobre ciertas áreas del dominio, entre ellas su franja más oriental, propició una primera tentativa de deslinde, de carácter provisorio, con la promesa de ampliar y matizar futuramente las observaciones allí recogidas. Esa primera línea divisoria con las variedades castellanas fue definida por Pidal tomando como guía los límites del antiguo reino, cuya frontera política con la vecina Castilla discurría de norte a sur en paralelo al curso del Pisuerga. En las décadas posteriores, fueron varios los dedicados discípulos que, imbuidos del espíritu pidaliano, se dieron con entusiasmo a la tarea de recopilar un volumen de datos mayor acerca de las áreas de transición (Blánquez, 1907; Krüger, 1914 y 1923; Sánchez Sevilla, 1928; Fink, 1929; Bierhenke, 1932), lo que permitió confirmar y puntualizar las notas germinales del maestro. A partir de entonces, la tendencia general fue, salvo excepciones, considerar de entrada como núcleo del dominio las provincias de León, Zamora y Salamanca (García de Diego, 1946; Alvar, 1996), con posibilidad de dilatar estos límites hasta los de las vecinas Cáceres y Santander (Zamora Vicente, 1960).

En esta coyuntura, es habitual, por un lado, no considerar las provincias de $\mathrm{Pa}$ lencia y Valladolid (Zamora Vicente, 1960), parte de cuyos territorios en la margen derecha del Pisuerga fueron también de dominio leonés y en cuya habla, hoy ya netamente castellana incluso en los municipios linderos con León y Zamora, tan solo pueden rastrearse meras huellas, esencialmente léxicas, de un antiguo influjo leonés ${ }^{1}$. Por otro, al igual que las variedades asturianas acostumbran a ser abordadas individualmente al margen de las foramontanas, las hablas de filiación leonesa extendidas por la Extremadura cacereña, cuya mitad occidental recibió un importante influjo lingüístico del reino norteño, han sido con frecuencia excluidas de las monografías dialectales leonesas por presentar una serie de peculiaridades que aconsejan su estudio separado como variedades de transición (Zamora Vicente, 1960; Alvar, 1996). Por último, hay quienes se han mostrado partidarios de contemplar dentro del contínuum de hablas leonesas el sector más occidental de la actual Cantabria (Zamora Vicente, 1960; Bustos Gisbert, 1987), cuyo tercio oeste hasta la frontera natural del Saja presenta, como se comentará más adelante (vid. 3.2.1.), ciertos tintes leoneses que han servido para postular una continuidad entre las variedades montañesas y las asturianas orientales (Echenique y Sánchez, 2005: 357).

Por otro lado, nadie ignora que aun cuando se acepta circunscribir el área del leonés a las provincias de León, Zamora y Salamanca, tampoco la totalidad de estos territorios presenta rasgos dialectales de filiación leonesa. En efecto, el gallego penetra con determinación por el oeste de León y Zamora al tiempo que los fenómenos dialectales castellanos son ya palpables en la franja más oriental de las tres provincias, con especial vitalidad en las de León y Salamanca. El castellano convive con el gallego en la zona de los Ancares leoneses, que atesora

${ }^{1}$ Para más datos, vid. Borrego (1999: 319) y Morala (2002 y 2011: 95). 
esa habla particular descrita por Alonso y García Yebra (1961); en la mitad oeste de El Bierzo en torno a Villafranca, con una zona fronteriza gallego-leonesa a lo largo de las dos vertientes del Cúa (García y García, 1999: 200); en el rincón más occidental de La Cabrera alrededor del término de Puente de Domingo Flórez (García del Castillo, 1957: 116), y, en fin, en los municipios sanabreses al oeste de Requejo. Nótese que estas áreas gallegófonas de León y Zamora son las que quedan delimitadas por la isoglosa que nace en la desembocadura del Navia y viene a morir en la frontera hispanolusa cerca de Hermisende, al oeste de la cual

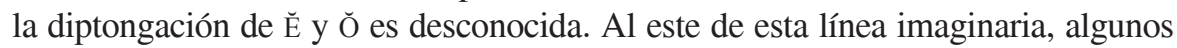
autores (Frías Conde, 1997: 248; Costas González, 2011 y 2012) aconsejan incluir también en el conjunto de hablas gallegas no propiamente portuguesas el falar de la localidad sanabresa de Calabor, que presenta concomitancias más estrechas con el gallego de los exclaves de Eljas, San Martín de Trevejo y Valverde del Fresno, en la sierra de Gata cacereña, que con el portugués fronterizo ${ }^{2}$. Si nos desplazamos, por otro lado, a la franja este de las citadas provincias, presenta un fuerte regusto castellano ${ }^{3}$ toda la zona oriental de León, desde el Alto Cea hasta la capital y desde aquí hasta la localidad zamorana de Benavente en paralelo al curso medio del Esla. En Zamora, quedan fuera el extremo nororiental de Tierra de Campos y el suroriental de La Guareña, mientras que en la de Salamanca se contemplan como esencialmente castellanos los campos de Cantalapiedra y Peñaranda, el sector este de las comarcas de Alba y Salvatierra, la integridad del Alto Tormes y el recodo oriental de la sierra de Béjar en torno al macizo de Vallejera.

El mapa resultante del dominio muestra, por tanto, un área más o menos amplia al norte que se ve progresivamente diezmada en sus flancos occidental y, en especial, oriental por el empuje del gallego y el castellano, hoy consolidado como lengua habitual de expresión en la totalidad de la zona. Los datos anteriores dejan, pues, traslucir cómo las fronteras externas del dominio se insubordinan tanto a las lindes del otrora reino leonés, que cobijaban áreas centrales de la meseta desde hace siglos exclusivamente castellanas, como a los modernos límites provinciales, trazados con arreglo a juiciosos criterios demográficos, económicos y orográficos, pero escasamente informativos para el estudio de unas fronteras linguísticas que vienen definiéndose desde muy antiguo.

\subsection{Las fronteras internas}

El espacio leonés delineado en el epígrafe anterior no constituye un bloque homogéneo, sino más bien una sucesión de micro-continua lectales (Chambers y

\footnotetext{
2 Para datos lingüísticos más precisos acerca de la frontera gallego-leonesa, vid. Seco Orosa (2001).

3 Siguiendo a Borrego (1996) y Morala (2011: 97 y ss.), se considerará como límite lingüístico oriental con las hablas castellanas la isoglosa al este de la cual se registran fenómenos de leísmo, laísmo y loísmo desconocidos por las hablas leonesas.
} 
Trudgill, 1994), más propiamente leoneses al norte y oeste del territorio y decididamente más castellanos a medida que se avanza hacia el sur y este del dominio. La propuesta de parcelación interna más aceptada por la comunidad científica ha sido trazada por Borrego (1996: 141 y ss.) sobre la base de los cinco fenómenos observados por Menéndez Pidal (1906) para marcar la transición de las variedades occidentales a las orientales. El mapa dialectal de Borrego (1996), que se tomará como base para su cotejo con la vieja carta eclesiástica peninsular, reconoce un total de cinco subáreas que, presentadas de mayor a menor grado de fuerza dialectal, exhiben los siguientes rasgos:

- La zona 1, aquella en la que las trazas dialectales se manifiestan con una mayor amplitud y vitalidad, se halla separada del gallego por la isoglosa

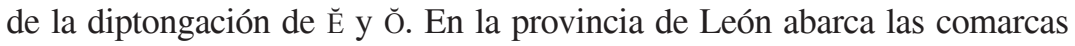
de Babia, Laciana, parte de Luna y Los Argüellos así como El Bierzo oriental y La Cabrera, mientras que en Zamora incluye únicamente la Baja Sanabria.

- La zona 2, en la que los rasgos anteriores se diluyen considerablemente, encuentra su límite oriental en la isoglosa de la conservación de los diptongos decrecientes /ei/ y /ou/, al este de la cual aparecen las variantes reducidas /e/ y /o/. Comprende las comarcas leonesas de Omaña, La Cepeda y La Maragatería junto con las zamoranas de La Carballeda y Aliste.

- La zona 3, donde la fuerza dialectal se ve rigurosamente menguada, constituye una estrecha franja vertical comprendida entre el límite de pervivencia de los diptongos decrecientes y la isoglosa al oeste de la cual se atestigua el mantenimiento de F-. Por lo que hace a la provincia de León, integran esta zona los altos valles del Porma, el Curueño y el Bernesga así como la ribera del Órbigo; en la provincia de Zamora, abarca el extremo noroccidental de Sayago y — a falta de datos más precisos_ probablemente también la margen occidental del Esla, el curso medio del Tera y el valle de Vidriales.

- La zona 4, en la que hoy solo perviven vestigios dialectales, se presenta como un área discontinua cuya única característica compartida es la conservación del resultado aspirado de F-. Por un lado, incluye los valles leoneses de Valdeón y Sajambre y, por otro, las comarcas salmantinas de La Ribera con el norte de El Abadengo, El Rebollar y las sierras de Gata y Francia.

- La zona 5, que acusa tan solo restos esporádicos de un leonés probablemente hablado en estas tierras en época lejana, comprende las áreas restantes de León, Zamora y Salamanca al oeste de la isoglosa que marca la vigencia de los fenómenos castellanos de leísmo, laísmo y loísmo. 


\section{HACIA UNA NUEVA CONCEPCIÓN DEL ESPACIO DIALECTAL LEONÉS}

\subsection{La diócesis como demarcación lingüística}

Sin negar la fuerza de la política territorial que durante siglos se realizó desde la vecina Castilla ni sus irremediables consecuencias lingüísticas para el dominio más occidental, se sugiere aquí alterar ligeramente el ángulo de visión para analizar el impacto que sobre la distribución dialectal pudieron tener otras divisiones de más rancia tradición y peso histórico, cuyos límites seculares sustentaron y fortalecieron lazos de pertenencia a una misma comunidad religiosa y ayudaron a definir las particularidades etnográficas de los territorios que flanqueaban. Ya Zamora Vicente (1987: 19) había insistido en esta posibilidad al advertir cómo hasta 1833 la organización fundamental del territorio español — salvo por el fallido conato de las prefecturas de 1810 y la división provisional de 1822 - no era civil sino eclesiástica, y radicaba en la diócesis como piedra angular de la administración. Si durante siglos esta había sido la división territorial esencial de la península, sin duda algo tendría que decir — como había vislumbrado Menéndez Pidal (1916: 82) — acerca de la fragmentación dialectal del país:

La relación que se descubre entre obispado y dialecto reconoce la antigüedad y estabilidad secular de las divisiones eclesiásticas, las cuales conservan primitivas divisiones étnicas, comerciales o administrativas del imperio romano; es decir, muestra que en la caracterización de los dialectos intervienen causas de la más remota antigüedad.

Menéndez Pidal ya había recurrido, de hecho, a este planteamiento en un intento de explicar la presencia del leonés en la portuguesa tierra de Miranda (1906: 20) o la proscripción del valenciano en ciertas comarcas del suroeste de Castellón (1908: 342). Múgica (1914-1917: 192) había apuntado también a esta posibilidad para dar cuenta de la distribución espacial de los tres grandes dialectos —altonavarro, vizcaíno y guipuzcoano- del euskara, argumento que con este mismo fin esgrimiría nuevamente Caro Baroja (1943 y 1945) en sus estudios históricos sobre la lengua vascongada. En el contexto románico, Morf (1911) había llamado, por su parte, la atención sobre la correspondencia de ciertos confines diocesanos con los límites entre el picardo y el francés y entre este y el franco-provenzal ${ }^{4}$, al tiempo que Tallgren (1913: 7 y ss.), en el esbozo de un malogrado proyecto de atlas románico histórico, había insistido en la conveniencia de que las fronteras lingüísticas se trazaran superpuestas no a las lindes civiles sino a las antiguas divisiones eclesiásticas. Naturalmente, la idea de unos límites lingüísticos que

\footnotetext{
4 En la reseña de Morf (1911), Ronjat (1912) reconoce, no obstante, haber detectado asimetrías significativas en la propuesta del romanista suizo que pondrían en entredicho la pretendida correspondencia entre límites lingüísticos y eclesiásticos (ibíd.: 421).
} 
reproducían con mayor o menor exactitud demarcaciones diocesanas herederas a su vez de antiguas fronteras hoy extintas resultaba cuando menos atractiva. No parece casual que la voz DICECSIS, con la que Diocleciano designó cada una de las regiones administrativas en que fragmentó el Imperio a principios del siglo IV, fuera posteriormente la adoptada por la Iglesia ante la necesidad de parcelar su territorio en circunscripciones menores. Así, por ejemplo, la DICECESIS de Gallæcia, demarcación primero administrativa y luego eclesiástica, delimitaba una zona con capital en la actual Braga que comprendía el norte de Portugal, Galicia y Asturias y que todavía hoy manifiesta una clara cohesión linguística y cultural (Echenique y Sánchez, 2005: 360-362; Morala, 2011: 110 y ss.). Llorente (1976: 18 y 24) comenta también cómo en las antiguas diócesis de Salamanca y Ciudad Rodrigo, muy semejantes a las actuales en cuanto a su demarcación, se espejan con extraordinaria fidelidad los límites de dos municipios de la Lusitania romana - Salmantica y Mirobriga - aun cuando la erección de esta última en sede episcopal no se verifica hasta el siglo XII ${ }^{5}$.

A la llegada de las provincias civiles en el primer tercio del XIX, la diócesis constituía una demarcación esencial en la centralizada monarquía española, cuya entidad era rastreable en términos religiosos, pero también demográficos, sociales, culturales y, significativamente, lingüísticos. Su trascendencia resultaba incontestable en una sociedad profundamente sacralizada hasta fechas no tan lejanas, en la que la autoridad eclesiástica pastoreaba no solo las almas del vulgo devoto, sino también las voluntades de la élite gobernante. No se pierda de vista, en este sentido, que las labores de parcelación eclesiástica de la península habían sido con frecuencia acometidas conjuntamente por obispos y reyes, que veían en esa sabrosa colaboración un medio para afianzar su respectivo estatus político y religioso (Martínez, 1994: 122).

La consecuencia más tangible de esa coyuntura histórica fue el establecimiento de unas circunscripciones que acabaron oficiando de facto como verdaderos límites administrativos y que encumbraron a sus respectivas sedes como centros homogeneizadores de la comunidad. Como ha señalado Trudgill (1992: 75), es plausible pensar que "speakers within a diocese would look to the diocesan capital for their linguistic standards and would travel to the capital rather than elsewhere for trading and administrative purposes. As a result, linguistic frontiers came to lie

\footnotetext{
5 Hay, no obstante, quien se muestra escéptico con la influencia que las divisiones prerromanas hayan podido ejercer sobre la ordenación lingüística de la península, argumentado que muchas de las primitivas fronteras diocesanas anteriores a la invasión musulmana hubieron de ser redefinidas en paralelo al avance cristiano merced a complejas causas cuyo análisis pormenorizado excedería con creces los objetivos de este trabajo (Martínez, 1994: 121). Así, por ejemplo, las conclusiones alcanzadas por Penny (1978) al examinar la posible influencia de las fronteras tribales prerromanas entre astures y cántabros sugieren que la distribución dialectal del asturiano-leonés y del castellano no obedece tanto a los límites prerromanos como a las políticas medievales que articularon el reparto entre León y Castilla.
} 
along political frontiers". El poder, la autoridad y en ocasiones la justicia, terrena y divina, habían de buscarse en la cátedra episcopal, que, auxiliada por la labor de los seminarios conciliares, se había convertido en eje difusor de los usos linguiísticos a través de los nuevos tonsurados (cfr. Morala, 2011: 110), circunstancia que ha llevado a algunos investigadores a reivindicar el papel de los párrocos en los procesos de singularización lingüística invocando su consideración como figuras de prestigio (Francisco Sánchez, 2017: 25). En cualquier caso, y frente a las objeciones que pudiera plantear una propuesta de tales características, quede claro que la finalidad de esta contribución no es analizar la labor desempeñada por el aparato humano de las diócesis en la propagación de determinadas particularidades lingüísticas, sino el peso de la demarcación episcopal en la configuración y fragmentación interna del espacio dialectal.

En este contexto, Morala (2011: 104 y ss.) se ha hecho eco del interés de atender específicamente al primitivo mapa eclesiástico de la península ibérica, cuyas diócesis no adecuaron sus límites a los de la división provincial hasta la suscripción en 1953 del Concordato entre la Santa Sede y España. El artículo IX del acuerdo, que entraría en vigor escalonadamente en los años posteriores, recogía la necesidad de redefinir las fronteras eclesiásticas para, por un lado, evitar que un mismo obispado comprendiera territorios de provincias civiles distintas a la de su sede episcopal y, por otro, compensar las desigualdades de superficie existentes entre ciertas diócesis (Martínez, 1994: 124). El objetivo de las páginas siguientes será evaluar en qué medida esos límites eclesiásticos pueden arrojar algo de luz sobre la variación linguiística en el contexto específico del dominio dialectal leonés.

\subsection{Límites eclesiásticos y fronteras lingüísticas: el caso del dominio leonés}

Tomando como patrón la organización episcopal anterior a 1960, en un primer subapartado se estudiará el área septentrional del territorio demarcada por las antiguas diócesis de Oviedo, León y Astorga. Por su parte, las particularidades del área meridional y, por tanto, de las antiguas circunscripciones de Santiago, Zamora, Salamanca y Ciudad Rodrigo serán analizadas en un segundo epígrafe. En una última sección, se abordará, en fin, el especial estatus de la esquina noroccidental del Trás-os-Montes portugués y de los enclaves occidentales del dominio que conocen la presencia del gallego.

\subsubsection{El norte del dominio: las diócesis de Oviedo, León y Astorga}

Hasta la reforma de 1953 y desde su erección, el báculo de Oviedo había administrado los territorios más septentrionales del dominio leonés. Según da- 
tos de Martínez (1994: 128), bajo su jurisdicción se hallaban un total de 165 parroquias repartidas por un lado entre Babia, Laciana, la ribera oriental del Sil, Luna y la cuenca alta del Bernesga, en la Montaña Occidental y Central de León, y, por otro, entre el exclave de Armellada, en la Ribera del Órbigo, y la Vicaría de San Millán, con epicentro en Benavente y jurisdicción sobre un pequeño número de feligresías leonesas y zamoranas de la vega del Esla ${ }^{6}$. En términos lingüísticos, las localidades de la franja más septentrional se adscriben, con la excepción de la comarca de Gordón, que de hecho no fue nunca gestionada en su totalidad por el prelado de Oviedo, a la zona 1 de Borrego (1996), en la que los rasgos dialectales manifiestan mayor amplitud y vitalidad y en la que el dialecto es percibido como un código autónomo y no como un castellano teñido de rasgos locales o comarcales. Por otro lado, se observa que este corredor montañoso queda más o menos delimitado en términos lingüísticos por la isoglosa que circunda por el sur, el este y el oeste el área de vigencia de las soluciones africadas para los grupos latinos L-, -LL-, -LY- y -C'L- descrita por Andrés Castellanos et al. (1957) en el Alto León. La frontera meridional de la diócesis de Oviedo se superpone al límite linguiístico que se extiende por el occidente hasta la ribera del $\mathrm{Sil}^{7}$ para remontar en dirección noreste hasta Salentinos y Murias de Paredes y descender en dirección a Riello, parroquias todas ellas en el confín del báculo ovetense (Martínez Vigil, 1892) (vid. Mapa $1)^{8}$. En otras palabras, la zona más dialectal se corresponde con un área administrada en lo eclesiástico — lo que hasta el siglo XIX supone decir también en lo civil— no desde León sino desde Oviedo.

${ }^{6}$ En León, las de Algadefe, Castrillino, Castrofuerte, Cimanes de la Vega, Lordemanos, Matilla, San Millán de los Caballeros, Toral de los Guzmanes, Valencia de Don Juan, Villademor, Villafer, Villamandos, Villaornate, Villaquejida y Villarrabines; en Zamora, las de Benavente, Matilla de Arzón, Santa Colomba de las Carabias, San Cristóbal de Entreviñas, San Miguel del Esla y Villanueva de Azogue (Madoz, 1849: passim).

7 Pertenecían a Oviedo las parroquias de Cuevas, Matalavilla, Palacios, Santa Cruz, Susañe, Tejedo, Valdeprado y Villarino, las cuales constituyen el límite suroccidental aproximado de las africadas.

8 Es significativo que Andrés Castellanos et al. (1957) registren soluciones africadas en Murias pero no en el vecino Vegapujín, de su mismo ayuntamiento pero dependiente ya de la diócesis astorgana. 


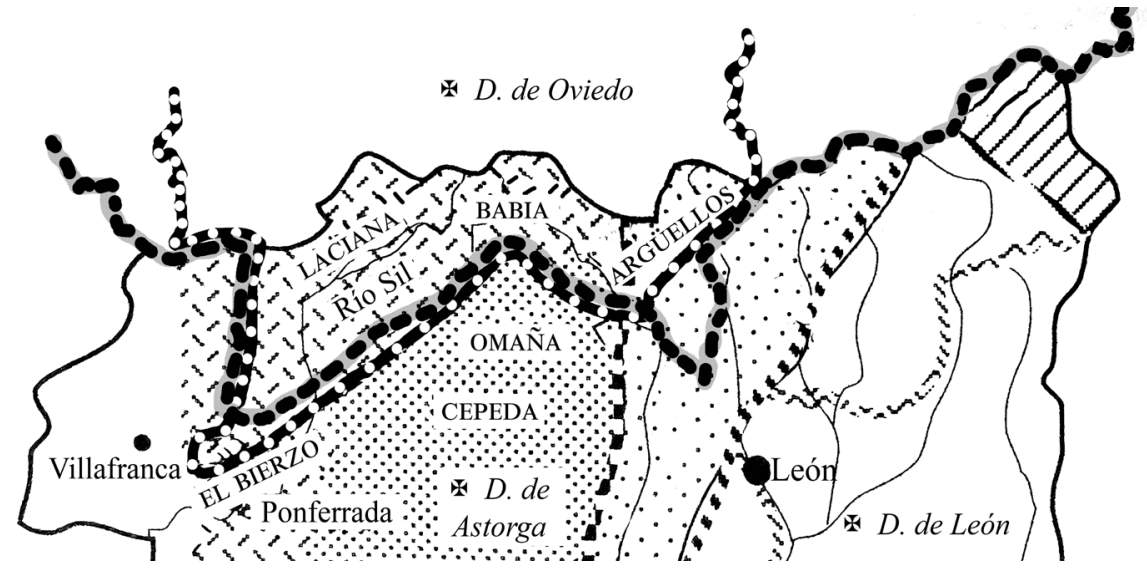

MAPA 1.-Límites de la antigua archidiócesis de Oviedo (negro discontinuo) y de las soluciones africadas en las variedades leonesas (negro con punteado blanco). Adaptado de Borrego (1996: 142).

Las comarcas a las que acaba de aludirse se hallaban significativamente alejadas de los dominios de la diócesis de León, cuya antigua circunscripción presentaba una extensión radicalmente distinta de la actual. Hasta la década de 1950 agrupaba la práctica totalidad de la provincia civil de León al este de la ciudad homónima, más de 150 parroquias repartidas por el tercio occidental de la provincia de Palencia a lo largo de la Montaña y la Vega de Valdavia (Martínez, 1994: 128), un total de 62 en los valles cántabros occidentales (ibíd.: 131), un pequeño número de feligresías en el extremo noroeste de Valladolid entre Mayorga y Villalón y la esquina nororiental de Zamora al norte de Villalpando9 (Fernández-Ordóñez 1994: 115), así como el exclave lucense de Triacastela ${ }^{10}$. Precisamente, esas áreas de Zamora y de León son las que, pese a encuadrarse en los límites del viejo reino, escapan del área dialectal y manifiestan, en cambio, fenómenos lingüísticos esencialmente castellanos que justifican su adscripción a la zona 5. En la provincia de León se trata de las comarcas comprendidas entre el curso medio de los ríos Torío y Esla por el oeste y Cea por el este, en cuyos municipios se registra, por ejemplo, un paradigma de clíticos no etimológico de transición (Fernández-Ordóñez, 1994: 94). Idéntica circunstancia es la de las localidades zamoranas del extremo nororiental de la Tierra de Campos, las únicas de la actual provincia en las que aflora un sistema referencial de clíticos.

${ }^{9}$ Concretamente, fueron leonesas las parroquias de Castroverde de Campos, Cerecinos de Campos, Cotanes del Monte, Prado, Quintanilla del Monte, Quintanilla del Olmo, San Esteban del Molar, San Miguel del Valle, Tapioles, Valdescorriel, Vega de Villalobos, Villalobos, Villalpando, Villamayor de Campos, Villanueva del Campo y Villar de Fallaves (Lera Maíllo, 2018: 739).

10 Desde época medieval, el curato de Triacastela había sido objeto de continuo litigio entre los prelados leonés y lucense, hasta el punto de haber establecido este último su propio Arcedianato de Triacastela en Lugo (Sánchez Herrero, 1978: 36; Reglero de la Fuente, 2016: 593; Martínez, 1994: 133). 
Como puede comprobarse, los límites de la penetración de este fenómeno por el norte del reino coinciden con los de la antigua demarcación episcopal leonesa (vid. Mapa 2), paralelismo desde el que Morala (2011: 106) ha querido explicar también el desgaste dialectal de este territorio, el cual resulta especialmente significativo en el caso de León por tratarse de la provincia con mayor conciencia de sus peculiaridades linguiísticas. En relación con ello, no debe desatenderse el papel desempeñado a lo largo de los siglos por la ciudad de León como centro difusor de la norma lingüística, primero leonesa a raíz del establecimiento de la corte en 910, más tarde castellana tras la anexión al reino vecino en 1230. No es casual que los resultantes procesos de leonesización y castellanización se dejaran sentir precisamente, al menos en los testimonios escritos de los que hoy se dispone, en los territorios gobernados desde la cátedra de León —entre ellos, como ha señalado Viejo Fernández (2005: 124-125), toda la ribera oriental del Esla_- pero no en el área bajo jurisdicción de las urbes episcopales de Astorga y Oviedo.

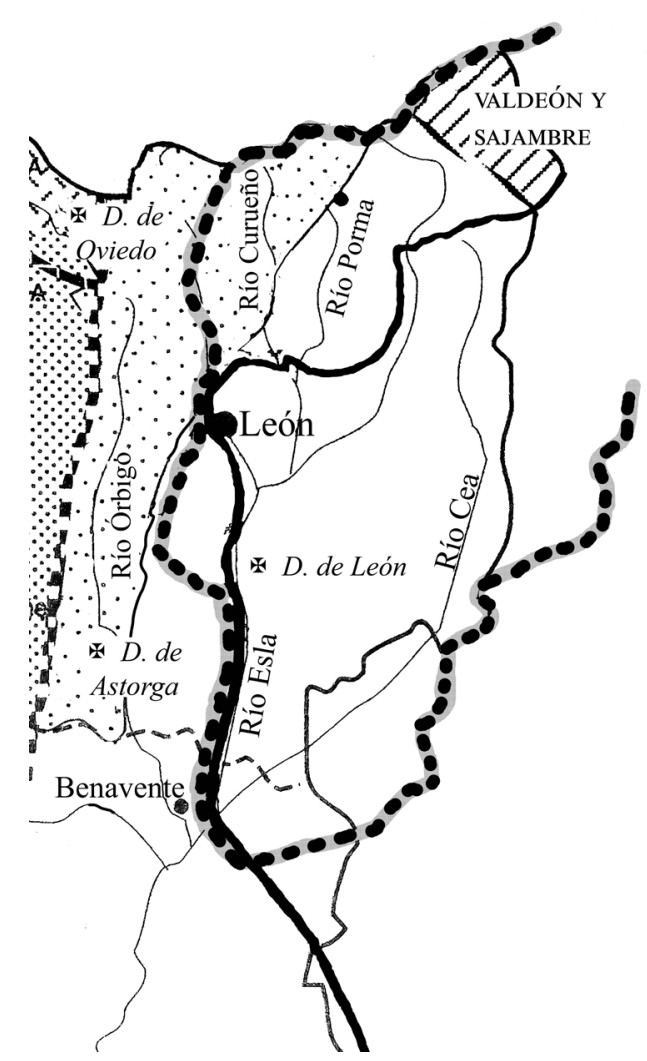

MAPA 2.-Límites de la antigua diócesis de León (negro discontinuo) e isoglosa del trueque de clíticos (negro continuo). Adaptado de Borrego (1996: 142). 
Como ya se comentó más arriba, la mitra de León tenía también a su cargo un total de 62 parroquias repartidas por los cuatro valles lebaniegos, hoy provincia de Cantabria (Martínez, 1994: 131). A grandes rasgos, este límite septentrional de la diócesis leonesa preconcordataria se amolda bien a la isoglosa que marca la vigencia de la palatalización de L- y de la aspiración de F- en los valles de Valdeón y Sajambre, el nacedero del Esla, la mitad oeste de Cantabria y parte de los pueblos del corredor más noroccidental de la montaña palentina, algunos de estos últimos adscritos también a León. Como es sabido, las hablas montañesas acusan los citados fenómenos en el recodo más suroccidental (Zamora Vicente, 1960: 118 y 122), con un área de especial intensidad que rebasa el límite eclesiástico leonés y se extiende también por las cuencas del Nansa y el Saja (Rodríguez Castellano, 1954). No se precisan conocimientos avanzados de Geografía para constatar que, contrariamente a lo esperado, las fronteras eclesiástica y lingüística coinciden aquí solo de forma parcial, algo que, por otro lado, concuerda bien con la histórica inestabilidad de este territorio en lo que atañe a su ordenación religiosa. La diócesis de Santander no se erige hasta mediados del siglo XVIII como unión de una serie de parroquias dependientes de Oviedo —en la mitad noroccidental de la actual provincia- y Burgos —en la fracción suroriental- Esta situación, que generó no pocos conflictos desde la creación de la frontera episcopal, quedó resuelta a finales del siglo XII, cuando Burgos absorbió la práctica totalidad de las posesiones ovetenses.

Sea como fuere, y aunque este razonamiento armonizaría plenamente con la hipótesis general, la ocupación de estos territorios por parte de un obispo castellano parece lo suficientemente temprana como para, de acuerdo con el hilo argumentativo seguido en este trabajo, considerarla decisiva a la hora de justificar un límite linguiístico como el de la realización glotal de F-. Con todo, en su propuesta de delimitación dialectal de la provincia de Cantabria, García Lomas (1949: 26-27) considera de influencia leonesa (y no asturiana) los valles lebaniegos hasta Lamasón, al tiempo que reconoce un sustrato bable al área costera hasta Santander. Es posible, que la presencia ovetense en la por entonces Asturias de Santillana y la leonesa en Liébana fueran determinantes en la configuración del castellano de este territorio (García Arias, 2010). En efecto, muchos de los rasgos del español hablado en Cantabria muestran hoy una distribución espacial que casa bien con el viejo límite episcopal: considérense, por ejemplo, los cierres vocálicos /e/ $>/ \mathrm{i} /, / \mathrm{o} />/ \mathrm{u} /$ o el escaso uso de formas compuestas en el centro y oeste provincial, fenómenos ambos coincidentes con las hablas asturiano-leonesas (Nuño Álvarez, 1996: 185 y 190).

Por último, las comarcas restantes del actual León y del norte de Zamora estuvieron regidas hasta mediados del siglo XX por la diócesis de Astorga. A su auspicio pastoral se acogían El Bierzo oriental, La Cabrera y Sanabria, 
todas ellas con un pronunciado componente dialectal propio de la zona 1; las de Omaña, La Cepeda, La Maragatería y La Carballeda, donde los rasgos dialectales conservan todavía, aunque en menor medida, cierta vigencia, y, por último, el curso medio del Tera, el valle de Vidriales y la margen oeste del Esla, que Borrego (1996: 150) incluye en la zona 3, haciendo notar no obstante la escasez de datos para apoyar esta adscripción. Es significativo el hecho de que la que fuera frontera oriental de la diócesis de Astorga hasta mediados del XX se situara coincidiendo en lo geográfico con la margen izquierda del Órbigo y en lo linguiístico con el flanco este del área dialectal. No se pierda de vista que una de las isoglosas fundamentales del leonés es la que atraviesa el dominio desde el valle alto del Porma hasta el rincón más suroccidental de Sayago, estableciendo el límite oriental de la conservación de F- y marcando el tránsito de un área que todavía presenta ciertos resabios dialectales (la zona 3) a otra plenamente castellana (la zona 5). Tras la restructuración del mapa eclesiástico en la década de 1950, los curatos de la Ribera del Órbigo y parte de los del Páramo ${ }^{11}$, que en lo lingüístico quedan a grandes rasgos abrazados al oeste por la isoglosa de los diptongos decrecientes y al este por la del mantenimiento de F-, pasaron a ser regidos por el prelado de la pulchra. No parece casual una vez más que los viejos límites diocesanos concuerden con los de ciertos fenómenos dialectales, más aún en el caso de la conservación de F-, hito que para Pidal marca el confín oriental del área de supervivencia dialectal ${ }^{12}$. Nótese, de hecho, también que la restructuración de la diócesis asturicense comportó, entre otras, la cesión a León de ciertas parroquias de Omaña que hoy preservan una notable identidad lingüística no por azar compartida con el resto de comarcas en otro tiempo tributarias de Astorga.

11 Alcoba, Azadón, Cabañeros, Carrizo de la Ribera, Cimanes del Tejar, Conforcos, Grajal de la Ribera, La Antigua, Laguna Dalga, Laguna de Negrillos, Llamas de la Ribera, Quintanilla de Sollamas, Ribera de Grajal, San Pedro de Dueñas, San Román de los Caballeros, San Salvador de Negrillos, Santa María del Páramo, Villaestrigo del Páramo, Villamor de la Laguna, Villanueva de Carrizo, Villaviciosa de la Ribera, Zambroncinos del Páramo y Zotes del Páramo (García Tato, 2018: 501).

12 Más allá de lo estrictamente fonético, Morala (2017: 359) ha llamado también la atención sobre las concomitancias léxicas entre las comarcas septentrionales y occidentales de la actual provincia de Zamora y las vecinas tierras de Astorga, separadas en lo civil pero unidas por el lazo eclesiástico. 


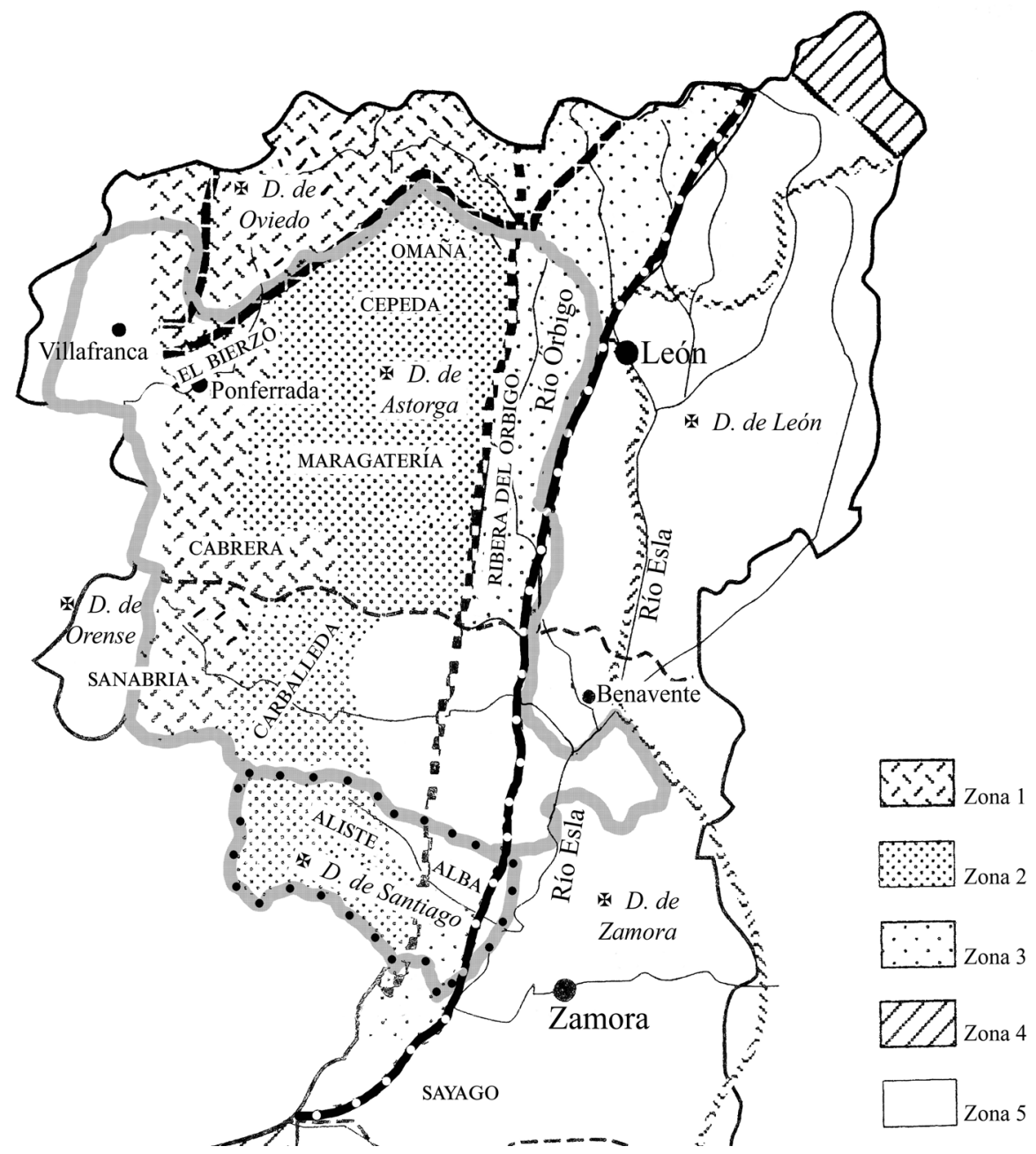

MAPA 3.-Límites de la antigua diócesis de Astorga (gris) y de la Vicaría de Alba y Aliste (gris con punteado negro) e isoglosa de la conservación de F- (negro con punteado blanco). Adaptado de Borrego (1996: 142).

3.2.2. El sur del dominio: las diócesis de Zamora, Ciudad Rodrigo y Salamanca

Con la excepción de la comarca zamorana de Aliste y de las salmantinas de La Ribera y El Rebollar, los territorios al sur de la diócesis de Astorga presentan una erosionada identidad dialectal que decrece significativamente hasta hacerse casi imperceptible en las diócesis históricas de Zamora y Salamanca. Estas úl- 
timas conocieron una castellanización ${ }^{13}$ relativamente temprana que favoreció el progresivo arrinconamiento del dialecto y su sustitución por los usos orientales irradiados desde las capitales. En estos territorios, los rasgos leoneses se reducen hoy a meras huellas, muchas ya solo escudriñables en el léxico y la toponimia, que contrastan con las ascuas dialectales aún latentes en la vecina diócesis de Ciudad Rodrigo, la cual, ligeramente resguardada al occidente, resistió con mayor firmeza el proceso castellanizador.

La primera excepción la constituye, como decimos, la comarca de Aliste, cuyo secular hermetismo y aislamiento geográfico propiciaron un mayor arraigo de los rasgos dialectales en comparación con otras zonas del centro y sur de la provincia. No es, en este sentido, azaroso que la mayor parte de las parroquias de Aliste y de la vecina Alba $^{14}$ junto con la localidad leonesa de Cacabelos, en El Bierzo gallegófono, conformaran desde el siglo XIII una vicaría dependiente del Arzobispado de Santiago de Compostela hasta su incorporación, en 1888, al Obispado de Zamora (Lera Maíllo, 2018: 742-743). Hasta la segunda mitad del XIX, la educación de los alistanos había sido, además, tutelada por quienes el habla popular había bautizado como galocheros, una suerte de maestros-campesinos de muy rudimentaria formación que, procedentes de Galicia y de León, se instalaban en la comarca durante los meses de invierno (Méndez Plaza, 1900: 47 y ss.). Sin duda, esa instrucción espiritual y temporal gestionada desde las regiones vecinas, de mayor fuerza dialectal, hubo de hacerse notar en el habla de los alistanos. En efecto, y a pesar de que muchos se hallan hoy en retroceso, los rasgos leoneses

13 Como oportunamente nos fue indicado por uno de los revisores anónimos del artículo, conviene aclarar que la castellanización histórica que se sostiene para estos territorios deriva de la información proporcionada por los testimonios escritos, muchos de ellos actos jurídicos redactados en una lengua notarial que rara vez deja traslucir las características del habla de la época. Así lo señala, por ejemplo, Morala (2017: 357) para la Zamora del siglo XVII, cuya cotidianidad lingüística probablemente aún habría de permanecer próxima al asturiano-leonés, como en efecto revela el análisis detallado tanto de esta última como de las informaciones — hoy históricas — de la dialectología de principios del XX, cuyas noticias muestran la pervivencia de rasgos no castellanos a menudo poco evidentes (íd.).

14 Alcañices, Alcorcillo, Arcillera, Arquillinos, Bercianos de Aliste, Bermillo de Alba, Brandilanes, Campogrande de Aliste, Carbajales, Carbajosa, Castillo de Alba, Castroladrones (Castro de Alcañices), Ceadea, Cerezal, Domez, El Poyo, Figueruela de Abajo, Figueruela de Arriba, Flechas, Flores, Fonfría, Fornillos de Aliste, Fradellos, Gallegos del Campo, Gallegos del Río, Grisuela, La Pueblica, Las Torres de Aliste, Latedo, Lober, Losacino, Losacio, Losilla, Mahide, Manzanal del Barco, Márquiz, Matellanes, Mellanes, Moldones, Moveros, Muga de Alba, Navianos, Nuez, Palazuelo, Pino del Oro, Pobladura de Aliste, Puercas, Rabanales, Rábano de Aliste, Ribas, Ricobayo, Riomanzanas, Samir de los Caños, San Blas, San Cristóbal de Aliste, San Juan del Rebollar, San Mamed, San Martín del Pedroso, San Martín del Terroso, San Pedro de las Cuevas, San Pedro de las Herrerías, San Vicente de la Cabeza, San Vicente del Barco, San Vitero, Santa Ana, Santa Eufemia del Barco, Sarracín de Aliste, Sejas de Aliste, Tola, Tolilla, Trabazos, Ufones, Valer, Vega de Nuez, Vegalatrave, Vide de Alba, Videmala, Villalcampo, Villarino de Cebal, Villarino de Manzanas, Villarino tras la Sierra, Viñas y Vivinera (Lera Maíllo, 2018: 743). 
pervivieron en la comarca de Aliste hasta bien entrado el siglo XX, siendo todavía en época actual fácilmente rastreables, en especial en el polo más occidental del territorio. Tanto es así que Borrego (1996) agrupa este territorio no con los enclaves centrales de la provincia, sino con las comarcas de La Carballeda zamorana y La Maragatería, La Cepeda y Omaña leonesas, todas ellas integradas en la zona 2, cuyo extremo oriental queda establecido por la isoglosa de vigencia de los diptongos decrecientes. La comarca inmediata de Alba, más oriental y en la que los trazos dialectales se ven significativamente diezmados ${ }^{15}$, se halla delimitada por la isoglosa que establece el término oriental tanto de la conservación de F- como de la palatalización de L-, las cuales discurren en paralelo desde el oeste de La Bañeza. En esta estrecha franja, Borrego (1996) cataloga como zona 3 los municipios que orbitan en torno a Videmala abrazados por las vegas del Aliste al norte y del Duero al sur, y como zona 5 el resto de feligresías albarinas de la antigua vicaría (vid. supra Mapa 3). En relación con las parroquias de la cátedra zamorana, poco más se puede comentar aparte del erosionado carácter dialectal que lleva a Borrego a englobar la totalidad de sus posesiones en la zona 5, con la sola excepción del conservador rincón noroccidental de Sayago en torno a Villadepera, donde no hace mucho el dialecto mantenía cierta salud (Borrego, 1981).

Con todo, a diferencia de lo que se dijo para León - y de lo que se dirá más adelante para Salamanca-, la provincia de Zamora no conoce en su extremo oriental la penetración del sistema referencial de clíticos, salvedad hecha del recodo de Tierra de Campos gestionado por la diócesis preconcordataria de León (vid. supra). La cuestión que aquí se plantea es, por tanto, la contraria: por qué en este caso la isoglosa del trueque de clíticos abandona el curso del Esla a la altura de Benavente y se desvía progresivamente hacia el este llegando a arropar a los municipios, hoy vallisoletanos, del límite más occidental de la Tierra del Vino y los Montes Torozos. Si se acude nuevamente al mapa eclesiástico, se constará que las poblaciones de esta estrecha franja, que rechazan todavía con cierta homogeneidad el sistema no etimológico de clíticos, formaron parte de la diócesis de Zamora hasta la suscripción del concordato $^{16}$. El Mapa 4, en el que se muestran superpuestos los dominios de la vieja circunscripción zamorana y el territorio actual de la provincia homónima, evidencia ese paralelismo:

15 Con todo, en la localidad albarina de Losacio, González Ferrero (2007) registra según los datos del ALPI ejemplos de lexicalización del diptongo ei, palatalización de N- y rotacismo en PL-, BL, CL-.

${ }_{16}$ Eran gobernadas desde Zamora las parroquias de Benafarces, Casasola de Arión, Caserío de Cubillas, Castromembibre, Castronuño, Mota del Marqués, Pedrosa del Rey, Pobladura de Sotiedra, San Pedro de Latarce, San Román de la Hornija, Tiedra, Villaester, Villafranca de Duero, Villalar, Villalbarba, Villardefrades y Villavellid (Lera Maíllo, 2018: 738-739). 


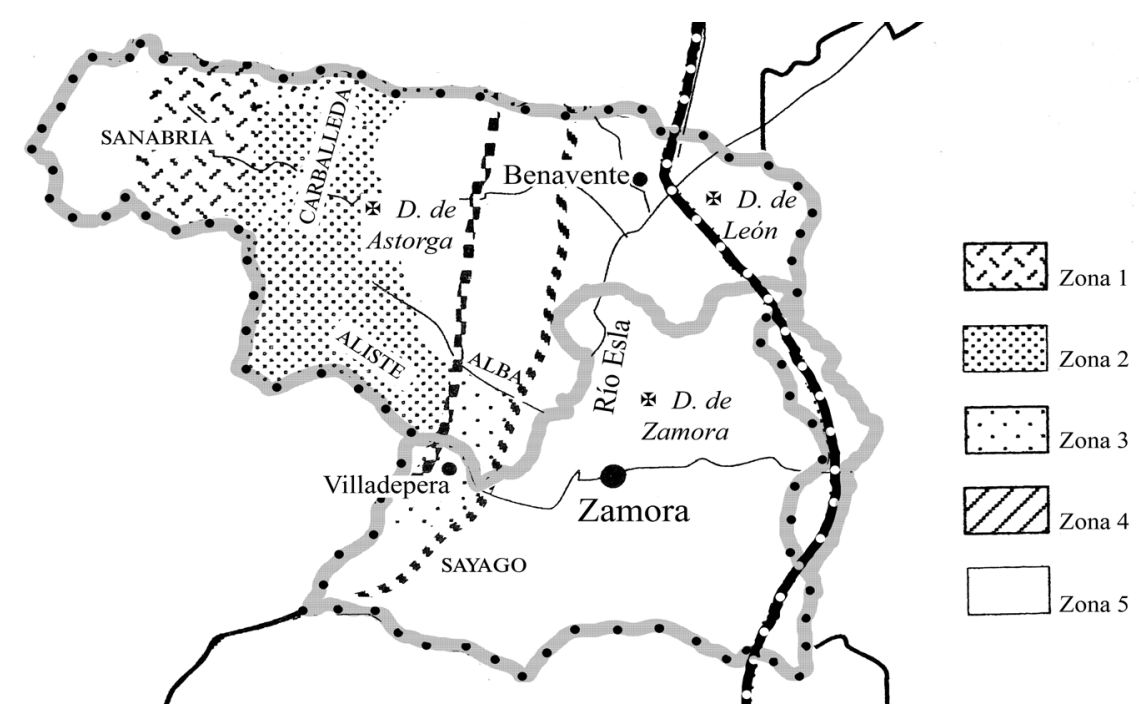

MAPA 4.-Límites de la antigua diócesis de Zamora (gris) y de la provincia homónima (gris con punteado negro) e isoglosa del trueque de clíticos (negro con punteado blanco). Adaptado de Borrego (1996: 142).

Cuando se desciende al otro lado del Tormes, con la excepción de la comarca de La Ribera, que perteneció en su totalidad al prelado de Salamanca ${ }^{17}$, la fuerza dialectal decrece considerablemente en toda la diócesis salmantina y solo aumenta de nuevo en la de Ciudad Rodrigo, cuyos límites conocieron únicamente cambios puntuales derivados de la restructuración preconciliar, tal vez por no existir en este caso la necesidad de adecuar el área de la diócesis a la de ninguna demarcación provincial homónima (lo mismo podría comentarse, de hecho, para la de Plasencia; vid. infra). El único lugar en que las antiguas fronteras de la Ciuitas Augusta franqueaban las civiles hasta el pasado siglo fue un recodo noroccidental en la vertiente cacereña de la sierra de Gata, precisamente aquel en el que más vivas se encuentran las variedades extremeñas de filiación leonesa y en el que se localizan us tres lugaris de habla gallega -Eljas, Valverde del Fresno y San Martín de Trevejo (Martín Benito, 2005: 533) — que tras la reforma pasarían a ser gestionadas por Coria ${ }^{18}$.

Volviendo a los límites de la provincia de Salamanca, cumple señalar la adscripción al báculo civitatense de la vecina comarca de El Rebollar, de marcada idiosincrasia lingüística frente al resto de la provincia. Este apartado rincón suroriental,

${ }^{17}$ Las parroquias riberanas de Mieza y Vilvestre, administradas hoy por la sede mirobrigense, no se desgajaron de la salmantina hasta la reordenación de mediados del XX (Martín Benito, 2005: 535).

18 Además de estas, fueron seccionadas de Ciudad Rodrigo e incorporadas a Coria las iglesias de Descargamaría, Trevejo, Robledillo de Gata y Villamiel (Martín Benito, 2005: 535), de manifiesto componente dialectal extremeño. 
cuyas localidades se asientan sobre la ladera septentrional de la sierra de Jálama y las estribaciones occidentales de la de Gata (Llorente, 1976: 67), manifiesta un fuerte conservadurismo en términos linguísticos, único en el conjunto de las hablas leonesas en la medida en que, por un lado, los rasgos leoneses orientales se manifiestan aquí mimetizados con fenómenos propios de las variedades extremeñas y, por otro, el dialecto — en el habla local palra - presenta usos diglósicos como código diferenciado del castellano (Iglesias Ovejero, 2010: 59), característica que comparte con el área gallegófona inmediata hasta hace escasas décadas administrada también por el prelado de Ciudad Rodrigo. Con la excepción de los enclaves rebollanos, que Borrego (1996) adscribe a la zona 4 atendiendo a factores linguísticos internos, y de su prolongación meridional por la vertiente cacereña de la sierra de Gata, el resto de la diócesis de Ciudad Rodrigo pertenece a la zona 5. Las generaciones ancianas de algunas de sus comarcas, como la franja más septentrional de El Abadengo que linda con La Ribera, mantienen aún hoy vivos ciertos fenómenos leoneses de los que la aspiración de F- o su conservación lexicalizada constituyen el ejemplo más representativo. El resto de la Charrería presenta solo puntualmente rasgos de adscripción leonesa compartidos con el occidente de la diócesis salamantina, siendo la diferencia fundamental con esta última la ausencia de ciertos fenómenos castellanos hoy plenamente consolidados en el este y suroriente de la actual provincia de Salamanca.

Deteniéndonos sobre esta última cuestión, conviene atraer la atención sobre el siguiente hecho: esas zonas de sustrato castellano del oriente salmantino, como el Alto Tormes o el este de la sierra de Béjar, eran jurisdicción respectiva de los diocesanos de Ávila ${ }^{19}$ y Plasencia ${ }^{20}$, circunscripciones ambas de habla propiamente castellana $^{21}$. Ello explica bien que toda su mitad oriental quede fuera de la zona 5 de Borrego (1996), la menos dialectal de las que se reconocen para el dominio leonés. En ese sector está asentado, por ejemplo, el sistema no etimológico de clíticos terciopersonales que también se extiende por el noroeste de la vecina Cáceres,

19 De báculo abulense fueron hasta 1958 las parroquias de Armenteros, Bercimuelle, Bóveda del Río Almar, Cespedosa de Tormes, Gallegos de Solmirón, Guijo de Ávila, Iñigo-Blasco, Mancera de Abajo, Salmoral, Cantaracillo y Rágama (Obispado de Salamanca, 1991: 112).

${ }^{20}$ Eran - y todavía hoy son — regidas por Plasencia las parroquias de Béjar, Candelario, Cantagallo, El Tejado, Fresnedoso de Béjar, Fuentebuena, Fuentes de Béjar, La Cabeza de Béjar, La Hoya, Ledrada, Nava de Béjar, Navacarros, Navalmoral de Béjar, Navamorales, Palomares, Peromingo, Puebla de San Medel, Puente del Congosto, Puerto de Béjar, San Medel, Sanchotello, Santibáñez de Béjar, Sorihuela, Valdelacasa, Valdesangil, Vallejera de Riofrío y Valverde de Valdelacasa.

21 Es probable que esta partición eclesiástica sea heredera de los límites políticos medievales. La sierra de Béjar había formado parte del concejo de Ávila y, por ende, del reino de Castilla y su repoblación había sido llevada a término con gentes procedentes mayormente del alfoz abulense, circunstancias que hubieron de repercutir en la caracterización cultural y lingüística de la zona (Llorente, 1976: 23). Nótese, de hecho, que las localidades relacionadas en las notas 19 y 20 se ubican ya en el área que recurre al sistema referencial de clíticos propio de las zonas castellanas colindantes (Fernández-Ordóñez, 1994: 17 y 46), tal como avalan los datos recogidos en Cespedosa de Tormes por Sánchez Sevilla (1928: 244 y ss.) y en Santibáñez de Béjar por Llorente (1986: 127). 
coincidiendo de nuevo en su confín occidental con el límite entre las diócesis de Coria y Plasencia (cfr. Fernández-Ordóñez, 1994: 88). La adscripción de Béjar y de su tierra a la antigua transierra castellana en lo espiritual y a Ávila en lo temporal justifica las peculiaridades lingüísticas de esta zona en relación con otros focos dialectales del sur de la provincia, como las vecinas sierras de Gata y Francia, donde los rasgos propios de las variedades meridionales del castellano se manifiestan aún hibridados con los relictos del viejo dialecto. En la sierra de Béjar, en cambio, las trazas leonesas son ya prácticamente inexistentes y se ven desplazadas por rasgos, mayormente fonéticos, propios del español meridional (Llorente, 1982: 92) que se prolongan por toda la vertiente sur del sistema montañoso en la provincia de Ávila.

En lo que aquí interesa, los municipios serranos al sur de la Peña de Francia y de la sierra de las Quilamas permanecieron hasta mediados del siglo XX bajo jurisdicción del Obispado de Coria $^{22}$ (Martín Hernández, 2005: 295). No por casualidad es precisamente en estos ayuntamientos donde Llorente (1976: 75) registra un habla y unas costumbres propiamente serranas y no charras, tal y como con posterioridad confirma Francisco Sánchez (2017, 2018 y 2019). Téngase presente que justo lo contrario ocurre en los pueblos de la vertiente septentrional de la orla montañosa, ya en la subcomarca inmediata de La Calería ${ }^{23}$, cuya habla, desprovista de marcas meridionales, es charra y no serrana y cuya cura de almas estuvo en manos de párrocos formados no en Plasencia, sino en Salamanca. A medio camino entre los enclaves serranos sureños, más dialectales, y los norteños, más castellanos, se extiende en fin un pequeño cinturón en torno a Monsagro en el que los rasgos meridionales se hallan ligeramente mitigados. Esta reducida área de transición queda dentro de la demarcación eclesiástica mirobrigense, cuya sustancia dialectal — se dijo- es mayor que la de la salmantina.

Llegados a este punto, a nadie habrá pasado inadvertido un dato que parece discordar con lo sosteniendo hasta el momento. La comarca salmantina de La Ribera, que junto con El Rebollar preserva una mayor fuerza dialectal, estuvo toda ella administrada en lo eclesiástico por el prelado de la fortis salmantina, hasta el punto de que la frontera comarcal coincide por el sur con el viejo límite interdiocesano entre Ciudad Rodrigo y la sede tormesina. La única excepción la constituye el municipio de Hinojosa de Duero, de habla netamente riberana (Llorente, 1946: 23) pese a ubicarse históricamente fuera de La Ribera más estricta e integrarse desde antiguo en la jurisdicción eclesiástica mirobrigense (Llorente, 1976). Las causas que explican la presencia

22 Concretamente, fueron gestionadas por la mitra cauriense hasta 1958 las parroquias de Aldeacipreste, Colmenar de Montemayor, Cristóbal, El Cerro, Horcajo de Montemayor, La Alberca, La Calzada de Béjar, Lagunilla, Martinebrón, Montemayor del Río, Peñacaballera, Pinedas, Valbuena, Valdefuentes de Sangusín, Valdelageve y Valdelamatanza (cfr. Obispado de Salamanca, 1991: 112).

${ }^{23}$ Esta subcomarca, que establece la transición entre la Sierra y la Charrería (el Campo Charro más La Armuña y Las Villas), comprende los términos de Escurial de la Sierra, La Rinconada, Navarredonda de la Rinconada y Linares de Riofrío, si bien este último es ya de habla serrana (Llorente, 1976: 157). 
de este reducto de rasgos leoneses en una diócesis que, como se ha visto, manifiesta un erosionado componente dialectal han de buscarse en mi opinión atendiendo no tanto a los límites eclesiásticos o políticos como a las particularidades geográficas, culturales y demográficas de este rincón fronterizo. En primer lugar, y al igual que ocurre con otras zonas de la Montaña de León en las que el dialecto se encuentra especialmente vivo, La Ribera es con diferencia la comarca más alejada de su cabeza de diócesis, amén de tratarse de un área deprimida, de tradición agrícola y hasta el pasado siglo deficientemente comunicada (Llorente, 1946: 25). Resulta obvio, por lo que toca a la amplitud y vitalidad del dilecto, que no se pretende asemejar aquí La Ribera a Babia o a Laciana — nada más desleal, por otra parte, a los datos linguísticos—, pero sí en cuanto al hecho de que ambas zonas han conservado cada una a su medida un particular carácter dialectal motivado por su recóndita ubicación geográfica. En el mapa dialectal de Salamanca, La Ribera constituye una zona conservadora de modo similar a como, en el contexto leonés, lo es la Montaña. Por otro lado, y a resultas de esa localización remota, la población riberana ha acusado un aislamiento mucho mayor en comparación con otras áreas de la diócesis, lo que ha propiciado entre sus habitantes la conciencia de poseer un carácter y un habla distintos a los de los demás salmantinos (Llorente, 1946: 30) ${ }^{24}$, afirmación que también puede sostenerse para El Rebollar.

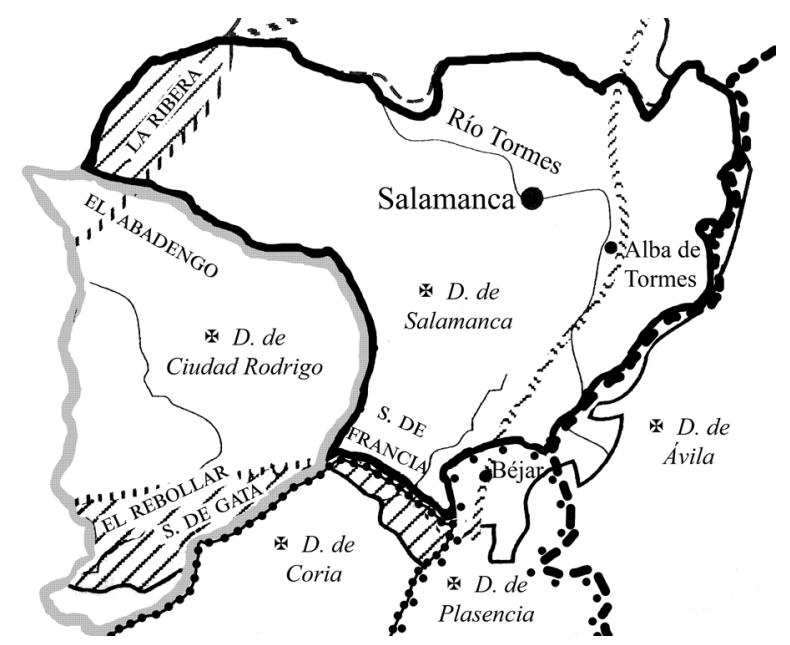

MAPA 5.-Límites de las antiguas diócesis de Ciudad Rodrigo (gris), Salamanca (negro), Coria (punteado y línea negros), Plasencia (punteado negro) y Ávila (negro discontinuo) sobre el mapa de la actual provincia de Salamanca. Adaptado de Borrego (1996: 142).

${ }^{24}$ El mismo Llorente comenta cómo "se da el caso curioso de que los niños de la escuela se pueden considerar como bilingües, desde el momento en que, hablando corrientemente en castellano bastante correcto, aunque pronunciado con la peculiar fonética riberana, pueden, si quieren, hablar dialectalmente, remedando a los rústicos o a sus propios abuelos, de cuya parla se mofan, pero la cual conocen perfectamente" (1946: 20). 
3.2.3. Los complejos límites del corredor oeste: gallego, portugués y leonés

Como ya se dijo, el gallego se oye en las provincias de León y Zamora a lo largo de una franja que recorre de norte a sur el extremo occidental de ambos territorios (vid. supra). De acuerdo con la idea que hasta aquí ha venido sugiriéndose, cabría esperar que en el trazado del límite entre gallego y leonés tomara también parte una vieja frontera episcopal que transcendiese los confines políticos de Galicia y arropase parte de las provincias vecinas. En efecto, un reducido número de las parroquias más occidentales de El Bierzo permanecieron, hasta su anexión a Astorga en 1953, en manos del prelado lucense ${ }^{25}$, mientras que las de la Alta Sanabria estuvieron bajo tutela del de Orense ${ }^{26}$. Con todo, el área de contacto del gallego-leonés se revela como un complejo dialectal en el que el deslinde entre sistemas linguiísticos y hablas de transición no es tarea sencilla y en el que, como ya apuntaron González Riaño y García Arias (2001: 26), los límites tanto dialectales como eclesiásticos han fluctuado en paralelo al devenir de los siglos evidenciando la cautela con que el concepto frontera debe manejarse en este territorio. Así, por ejemplo, el límite entre las hablas gallegas y las leonesas de El Bierzo definido por Marcet Rodríguez (2001) a partir de los datos de la geografía lingüística une la localidad ancaresa de Balouta con la cabreiresa de Vega de Yeres englobando, por tanto, en su flanco oeste un importante número de feligresías de habla gallega y secular dominio asturicense. Igualmente, las feligresías de Suárbol y Balouta, ambas en el extremo de la comarca de Ancares en el que convergen los confines de León, Galicia y Asturias, y que pese a haberse hallado bajo la mitra ovetense, presentan un decir ya puramente gallego, aunque con marcadas particularidades comarcales.

Algo similar cabe mencionar, en fin, para algunos enclaves fronterizos del rincón nororiental de la región portuguesa de Trás-Os-Montes en torno a Miranda do Douro y Sendim, cuyos falares han sido considerados desde los inicios de la dialectología ibérica como propiamente leoneses y cuyo acervo cultural presenta, de hecho, lazos más estrechos con Aliste y Sayago que con Braganza. Entre las causas que explican esta filiación linguística, Menéndez Pidal (1906: 20) apuntaba al gobierno eclesiástico ejercido desde Astorga hasta la fundación del reino de Portugal en 1139, al tiempo que Carvalho (1952: 269) aludía a una colonización ejercida en el siglo XIII desde los monasterios de San Martín de Castañeda, en Sanabria, y Santa María de Moreruela, en la ribera del Esla, así como de la Orden

25 Ambasmestas, Balboa, Barjas, Busmayor, Canteijeira, Castro, Corrales, Faba, Gestoso, Hermide, Lindoso, Lusio, Parada de Soto, Pereje, Portela, Pradela, Ransinde, San Fiz do Seo, Sotelo, Sotoparada, Trabadelo, Valcarce, Vega de Valcarce, Villafeile, Villar de Corrales, Villarrubín y Villasinde (García Tato, 2018: 501).

26 Aciberos, Castrelos, Castromil, Chanos, Hedroso, Hermisende, La Tejera, Las Hedradas, Lubián, Padornelo, San Ciprián y Villanueva de la Sierra (García Tato, 2018: 501). 
del Temple establecida en Alcañices, afirmaciones que deben ser consideradas en cualquier caso con prudencia. Tal como matiza Menéndez Pidal (1960: LIII), el peso lingüístico de esa colonización monástica hubo de ser menor que el pretendido por Carvalho (1952); en primer lugar, porque esta se produjo en un momento en el que las hablas leonesas no habrían tenido simplemente que establecerse en la zona, sino que superponerse y desbancar a las gallego-portuguesas; en segundo, porque desde que el control leonés llegara a su fin en torno al siglo XV, el dialecto mantuvo una notable vitalidad, la cual, según el autor, debe mucho a las particularidades orográficas del territorio, duramente aislado de la capital brigantina pero abierto, en cambio, a la vecina Aliste.

\subsection{Recapitulación}

En las páginas precedentes se ha pretendido mostrar cómo la propuesta planteada no parece ir desencaminada en su intento de explicar la variación intra e interdialectal atendiendo a razones históricas distintas de las tradicionalmente observadas. Si bien es cierto que el análisis anterior no revela, como cabría esperar, una correspondencia exacta entre isoglosas dialectales y límites episcopales, también lo es que este se acomoda con bastante docilidad a la extensión, en apariencia arbitraria, de ciertos fenómenos leoneses, difícil de explicar con éxito desde la horma de la división provincial. Para una visión de conjunto, se ofrece a continuación un mapa que refleja el territorio de las diócesis del dominio leonés según los datos de Méndez ( $c a$. 1891) junto con los límites provinciales actuales y las isoglosas fundamentales que marcan la vigencia de los fenómenos leoneses a los que se ha aludido en este trabajo ${ }^{27}$.

27 En el mapa no se marcan, por considerarlo escasamente informativo en términos lingüísticos, las parroquias dependientes del disuelto Priorato de San Marcos de León, una diócesis fragmentaria regida hasta 1873 por la Orden de Santiago y con jurisdicción sobre las parroquias leonesas de Campo de Villavidiel, Destriana y Santovenia de San Marcos; sobre las zamoranas de Barjacoba, Cubillos, Fontanillas de Castro, Olmillos de Castro, Peñausende, Perilla de Castro, Pías, Piedrahita de Castro, Porto, San Agustín, San Cebrián de Castro y Villalba de la Lampreana, y sobre las salmantinas de Barceíno, Barceo, Barreras, Barruecopardo, Cerezal de Peñahorcada, El Milano, Peralejos de Abajo, Saldeana, Saucelle, Valderrodrigo y Villasbuenas. 


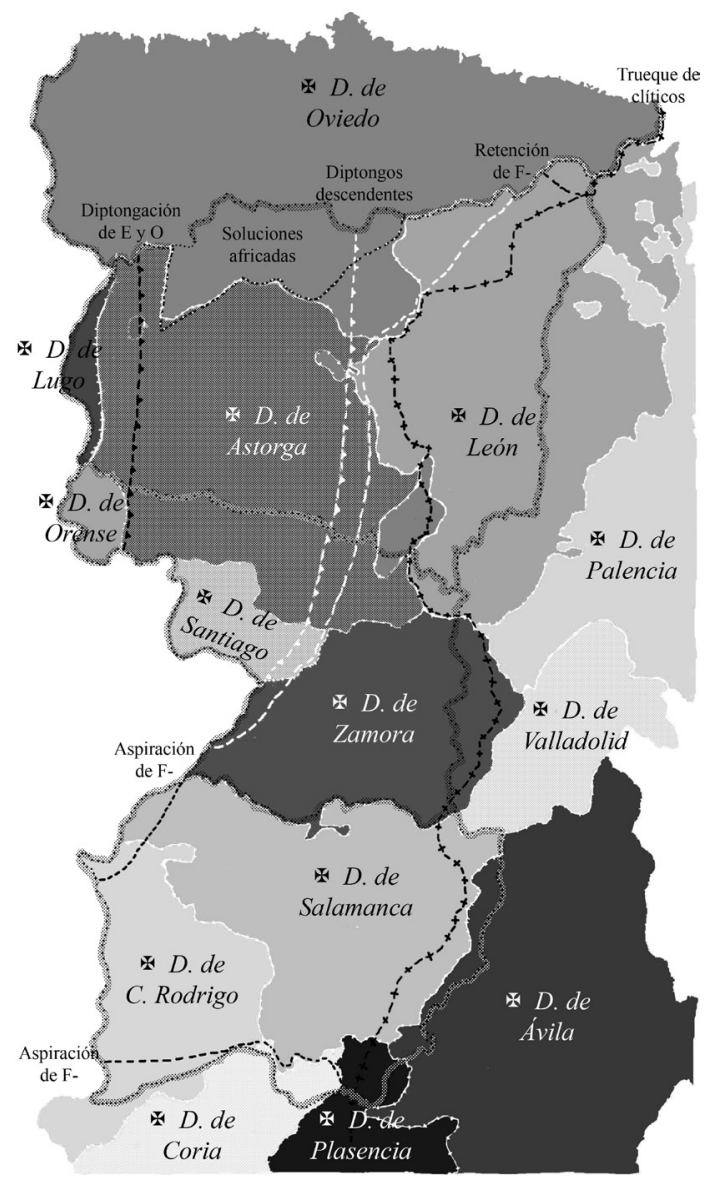

MAPA 6.-Diócesis españolas en 1888 e isoglosas lingüísticas del leonés. Según datos de Méndez (ca. 1891), Zamora Vicente (1960) y Borrego (1996). Se marcan los límites provinciales (punteado negro), de la diptongación de $\breve{\mathrm{E}}$ y Ŏ (línea y punta discontinuos negros),

de los diptongos descendentes (línea y punta discontinuos blancos), de la conservación de

F- (línea blanca discontinua), de la aspiración de F- (línea negra discontinua), del trueque de clíticos (línea y cruz negra) y de las soluciones africadas (línea negra con punteado blanco).

\section{CONClusiones}

Partiendo de las observaciones de Menéndez Pidal (1906), Zamora Vicente (1987) y Morala (2011), este artículo ha evaluado la influencia que las antiguas demarcaciones diocesanas pudieron ejercer en la configuración del espacio lingüístico leonés, tomando como base la división dialectal de Borrego (1996) y el mapa eclesiástico peninsular anterior a la reordenación de mediados del siglo XX. 
De manera general, el análisis revela una correspondencia fiel —manejando este término con generosidad- entre límites dialectales y fronteras diocesanas que concuerda con las áreas de dispersión, en apariencia arbitrarias, de determinados fenómenos lingüísticos.

En efecto, las zonas de mayor fuerza dialectal —esto es, la montaña occidental y central de León - se someten con bastante exactitud a los límites de la antigua diócesis de Oviedo, al tiempo que las comarcas de El Bierzo oriental, La Cabrera y la Baja Sanabria forman unidad todas ellas junto con Omaña, La Cepeda, La Maragatería, la Vega del Órbigo y La Carballeda en la diócesis de Astorga, donde el componente dialectal se preserva aunque acusando un notable desgaste. En la provincia de Zamora, la conservadora comarca de Aliste formó junto con la de Alba circunscripción propia dependiente del Arzobispado de Santiago, mientras que el resto de la provincia, de escaso componente dialectal, estuvo regida por la mitra zamorana. Más al sur, la diócesis de Ciudad Rodrigo muestra por lo general un carácter dialectal más marcado que la de Salamanca, con excepción de la franja de La Ribera. Por otro lado, la frontera con los fenómenos propios del español meridional, que avanzan con firmeza por la vertiente sur de las sierras salmantinas, coincide con incontestable fidelidad con las viejas lindes de los obispados de Coria y Plasencia. Por el oeste, se constata que parte de la franja occidental de León y Zamora de habla gallega fue jurisdicción de los prelados lucense y orensano, mientras que el tercio este del dominio, hoy esencialmente castellano, se ajusta bien a los límites de la antigua diócesis de León al norte, a los de la de Zamora en el centro y a los de la de Salamanca al sur. Parte del territorio más oriental de esta última, donde están ya asentados fenómenos dialectales puramente castellanos, fue de hecho hasta hace escasas décadas de dominio pastoral abulense.

Quede claro, en cualquier caso, que no se pretende aquí asignar a la organización eclesiástica de la península una responsabilidad exclusiva en la distribución espacial de las variedades leonesas. El objetivo es insistir en la conveniencia de conceder una atención mayor a la capacidad explicativa de las fronteras eclesiásticas — por lo general más antiguas y estables que las políticas - para dar cuenta de la particular configuración de un dominio dialectal como el leonés, cuyos límites intralingüísticos muestran una quietud mayor que en las vecinas variedades asturianas, donde la complejidad de las isoglosas dificulta definir con rigor fronteras internas (Penny, 2003). El enfoque adoptado no viene, por tanto, a desplazar sino a complementar, en paralelo al devenir histórico, las teorías que tradicionalmente han explicado la fragmentación dialectal del territorio, para la que en rara ocasión es acertado hablar de causas únicas.

Los resultados que aquí se presentan son, en fin, fácilmente cotejables mediante su extrapolación a otros dominios dialectales, tanto en lo que se refiere a las variedades internas del castellano como a los límites entre este y las lenguas circunvecinas o a las variantes diatópicas de estas últimas. No es casual, por 
ejemplo, que el valenciano, cuyo territorio natural de expansión se corresponde esencialmente con la franja costera de Castellón, Valencia y Alicante, sea la lengua de uso habitual en la mayor parte de la provincia de Castellón, adscrita a la antigua diócesis catalana de Tortosa, pero no, por ejemplo, en los territorios más occidentales de Valencia, en otro tiempo gobernados por un obispo sufragáneo de Zaragoza (Menéndez Pidal, 1908: 342; Zamora Vicente, 1982: 27-28, 1987: 19). De hecho, sin abandonar el dominio catalán y valenciano, algo parecido podría decirse también para la antigua circunscripción de Orihuela y, sin duda, el razonamiento podría aplicarse a otros dominios como el andaluz, para el que Morala (2011: 105) sugiere relacionar, por ejemplo, el color castellano de las hablas de Jaén y del noroeste de Granada con la subordinación de los ordinarios de Jaén, Guadix y Baza al metropolitano de Toledo. Sea como fuere, estas conjeturas, cuyo desarrollo exige la dedicación específica de un trabajo que excedería los objetivos del presente, no pueden ser aquí más que planteadas, legando a futuras investigaciones la tarea de corroborarlas o enmendarlas a la luz de los hechos lingüísticos.

\section{BIBLIOGRAFÍA}

ALCyL = Alvar, Manuel (1999): Atlas Lingüístico de Castilla y León, 3 ts., Valladolid, Junta de Castilla y León.

Alonso, Dámaso y Valentín García Yebra (1961): "El gallego-leonés de Ancares y su interés para la dialectología portuguesa", Cuadernos de Estudios Gallegos, XLVIII, pp. 43-79.

ALPI = Navarro Tomás, Tomás (dir.): Atlas Lingüístico de la Península Ibérica, Madrid, CSIC.

Alvar, Manuel (dir.) (1996): Manual de dialectología hispánica. El Español de España, Barcelona, Ariel.

Andrés Castellanos, María Soledad, Pilar Tolosa, Milagros Mozún e Isolina Sánchez Regueira (1957): "Límites de palatales en el Alto León", en Álvaro Galmés de Fuentes y Diego Catalán (dirs.), Trabajos sobre el dominio románico leonés, I, Madrid, Gredos, pp. 23-39.

Bierhenke, Wilhelm (1932): Ländliche Gewerbe der Sierra de Gata, Hamburg, Seminar für romanische Sprachen und Kultur.

Blánquez Fraile, Agustín (1907): "Límites del dialecto leonés occidental en Alcañices, Puebla de Sanabria y La Bañeza”, en Junta para la Ampliación de Estudios, Memoria correspondiente al año 1907, Madrid, Hijos de M. Tello, pp. 67-78.

Borrego Nieto, Julio (1981): Sociolingüística rural. Investigación en Villadepera de Sayago, Salamanca, Universidad de Salamanca.

Borrego Nieto, Julio (1996): “Leonés”, en Manuel Alvar (dir.), Manual de dialectología hispánica. El Español de España, Barcelona, Ariel, pp. 139-158.

Borrego Nieto, Julio (1999): "Salamanca en el conjunto de las hablas de Castilla y León”, Salamanca. Revista de Estudios, XLIII, pp. 297-321.

Bustos Gisbert, Eugenio (1987): "Las variedades dialectales y regionales en Castilla y León", en Eufemio Lorenzo Sanz (dir.), Castilla y León, Valladolid, Junta de Castilla y León, pp. 338-355.

Caro Baroja, Julio (1943): Los pueblos del norte de la Península Ibérica (Análisis histórico-cultural), Madrid, CSIC.

Caro Baroja, Julio (1945): Materiales para una historia de la lengua vasca en su relación con la latina, Salamanca, Universidad de Salamanca. 
Carvalho, José Gonçalo Herculano de (1952): "Porque se falam dialectos leoneses em terras de Miranda?", Revista Portuguesa de Filologia, V, 1/2, pp. 265-281.

Chambers, Jack y Peter Trudgill (1994): La dialectología, Madrid, Visor.

Concordato entre la Santa Sede y España = Inter Sanctam Sedem et Hispaniam Sollemnes Conventiones, Ciudad del Vaticano, 27 de agosto de 1953, <http://www.vatican.va/roman_curia/ secretariat_state/archivio/documents/rc_seg-st_19530827_concordato-spagna_sp.html>.

Costas González, Xosé Henrique (2011): A lingua galega no Eo-Navia, Bierzo Occidental, As Portelas, Calabor e o Val do Ellas, A Coruña, Real Academia Galega.

Costas González, Xosé Henrique (2012): "Notas sobre a fala galega de Seabra: o calaborés", en Xosé Bieito Arias Freixedo, Xosé María Gómez Clemente y Gabriel Pérez Durán, Sementar para os que veñan: Homenaxe a Camiño Noia, Vigo, Universidade de Vigo, pp. 45-65.

Echenique Elizondo, María Teresa y Juan Sánchez Méndez (2005): Las lenguas de un Reino. Historia lingüística hispánica, Madrid, Gredos.

Fernández-Ordóñez, Inés (1994): "Isoglosas internas del castellano. El sistema referencial del pronombre átono de tercera persona", Revista de Filología Española, LXXIV, 1/2, pp. 71-125, <https://doi.org/10.3989/rfe.1994.v74.i1/2.499>.

Fernández-Ordóñez, Inés (2012): "El norte peninsular y su papel en la historia de la lengua española", en Sara Gómez Seibane y Carsten Sinner (coords.), Estudios sobre tiempo y espacio en el español norteño, San Millán de la Cogolla, Cilengua, pp. 23-68.

Fink, Oskar (1929): Studien über die Mundarten der Sierra de Gata, Hamburg, Friederichsen, de Gruyter \& co.

Francisco Sánchez, Gonzalo (2017): El habla de la Sierra de Francia en su contexto geográfico, histórico y social, Salamanca, Instituto de las Identidades / Diputación de Salamanca.

Francisco Sánchez, Gonzalo (2018): "La nueva realidad social y demográfica rural castellana. El caso de la Sierra de Francia salmantina: metodología y observaciones lingüísticas", Lingüística Española Actual, XL, 1, pp. 111-135.

Francisco Sánchez, Gonzalo (2019): "Fonética y morfosintaxis del vernáculo de la Sierra de Francia (sur de Salamanca). Una aproximación histórica y sociolingüística", Dialectologia, XXII, pp. 31-56, <https://doi.org/10.1344/dialectologia2018.22.3>.

Frías Conde, Xavier (1997): "Sobre os bloques dialectais do galego. Unha nova proposta", Revista de Filología Románica, XIV, 1, pp. 241-256.

García Arias, Xosé Lluis (2010): "Llectura dialeutal de Cantabria", Lletres Asturianes, CII, pp. 7-33.

García de Diego, Vicente (1946 [1978]): Manual de dialectología española, $3^{a}$ ed., Madrid, Ediciones Cultura Hispánica.

García del Castillo, Juan (1957): "El habla de La Cabrera Baja", en Álvaro Galmés de Fuentes y Diego Catalán (dirs.), Trabajos sobre el dominio románico leonés, I, Madrid, Gredos, pp. $87-128$.

García Lomas, G. Adriano (1949): El lenguaje popular de las montañas de Santander, Santander, Centro de Estudios Montañeses.

García Tato, Isidro (2018): "La diócesis de Astorga en la época contemporánea”, en José Sánchez Herrero (coord.), Historia de las diócesis españolas: Astorga y Zamora, XXI, Madrid, Biblioteca de Autores Cristianos, pp. 367-720.

García y García, Jesús (1999): "Los límites históricos entre el gallego y el leonés en El Bierzo", en José Enrique Martínez Fernández (coord.), Trilcedumbre. Homenaje al profesor Francisco Martínez García, León, Universidad de León, pp. 197-206.

González Ferrero, Juan Carlos (2007): "Límites del dialecto leonés en la provincia de Zamora según los materiales del Cuaderno I del ALPI (1934-1935)", Revista de Dialectología y Tradiciones Populares, LXII, 2, pp. 165-206, <https://doi.org/10.3989/rdtp.2007.v62.i2.39>.

González Riaño, Xosé Antón y Xosé Lluis García Arias (2001): Estudiu sociollingüísticu de Zamora (fastera occidental), Oviedo, Academia de la Llingua Asturiana. 
Iglesias Ovejero, Ángel (2010): "Situación del habla de El Rebollar (Salamanca): Analogías y contrastes con las hablas extremeñas", Lletres Asturianes, CIII, pp. 35-59.

Krüger, Fritz (1914): Studien zur Lautgeschichte Westspanischer Mundarten, Hamburg, Gräfe \& Sillem.

Krüger, Fritz (1923): El dialecto de San Criprián de Sanabria: monografía leonesa, Madrid, Sucesores de Hernando.

Lera Maíllo, José Carlos de (2018): "Geografía eclesiástica de la diócesis (siglos X-XVII)", en José Sánchez Herrero (coord.), Historia de las diócesis españolas: Astorga y Zamora, XXI, Madrid, Biblioteca de Autores Cristianos, pp. 723-772.

Llorente Maldonado de Guevara, Antonio (1946): Estudio sobre el habla de La Ribera (comarca salmantina ribereña del Duero), Salamanca, CSIC.

Llorente Maldonado de Guevara, Antonio (1976): Las comarcas históricas y actuales de la provincia de Salamanca, Salamanca, Centro de Estudios Salmantinos.

Llorente Maldonado de Guevara, Antonio (1982): "El habla de Salamanca y su provincia", Boletín de la Asociación Europea de Profesores de Español, XXVI, pp. 91-100.

Llorente Maldonado de Guevara, Antonio (1986): "Las hablas vivas de Zamora y Salamanca en la actualidad", en Manuel Alvar (coord.), Lenguas peninsulares y proyección hispánica, Madrid, Fundación Friedrich Ebert / Instituto de Cooperación Iberoamericana, pp. 107-131.

Madoz, Pascual (1849): Diccionario geográfico-estadístico-histórico de España y sus posesiones de ultramar, Madrid, edición del autor.

Marcet Rodríguez, Vicente José (2001): "La frontera lingüística de El Bierzo", en José Antonio Bartol Hernández, Salvador Crespo Matellán, Carmen Fernández Juncal, Carmen Pensado, Emilio Prieto de los Mozos y Nieves Sánchez González de Herrero (eds.), Nuevas aportaciones al estudio de la lengua española. Investigaciones filológicas, Salamanca, Luso-Española de Ediciones, pp. 265-275.

Martín Benito, José Ignacio (2005): “La Iglesia de Ciudad Rodrigo”, en Teófanes Egido López (coord.), Historia de las diócesis de España: Ávila, Salamanca y Ciudad Rodrigo, XVIII, Madrid, Biblioteca de Autores Cristianos, pp. 321-584.

Martín Hernández, Francisco (2005): "La Iglesia de Salamanca", en Teófanes Egido López (coord.), Historia de las diócesis de España: Ávila, Salamanca y Ciudad Rodrigo, XVIII, Madrid, Biblioteca de Autores Cristianos, pp. 209-319.

Martínez, Mateo (1994): "La organización del espacio diocesano en la Historia de Castilla y León", Investigaciones históricas: Época moderna y contemporánea, XIV, pp. 119-136.

Martínez Vigil, Ramón (1892): Cuadro sinóptico de las parroquias del Obispado de Oviedo según la circunscripción hecha por el Excmo. y Rmo. Sr. Dr. D. F. R. Martínez Vigil, Oviedo, Vicente Brid.

Méndez, José (ca. 1891): Mapa de la división eclesiástica de España: formado con los datos oficiales y los facilitados por los Ilmos. Sres. Prelados a Don José Méndez, Madrid, Instituto Geográfico Nacional, <https://www.ign.es/web/catalogo-cartoteca/resources/html/003428.html>.

Méndez Plaza, Santiago (1900): Costumbres comunales de Aliste, Madrid, Imprenta del Asilo de Huérfanos del Sagrado Corazón de Jesús.

Menéndez Pidal, Ramón (1906 [1962]): El dialecto leonés. Prólogo, notas y apéndices de Carmen Bobes, Oviedo, Instituto de Estudios Asturianos.

Menéndez Pidal, Ramón (1908): "Sobre los límites del valenciano: A propósito de J. Hadwiger: Sprachgrenzen und Grenzmundarten des Valencianischen", en Primer Congrés Internacional de la Llengua Catalana, Barcelona, Joaquim Horta, pp. 340-344.

Menéndez Pidal, Ramón (1916): "Nota bibliográfica de Griera i Gaja, Antoni (1914): La frontera catalano-aragonesa. Estudi geogràfico-lingüístic, Barcelona, Institut d'Estudis Catalans", Revista de Filología Española, III, pp. 73-88.

Menéndez Pidal, Ramón (1960): "Repoblación y tradición en la cuenca del Duero", en Manuel Alvar, Antonio Badía, Rafael de Balbín y Luís Filipe Lindley Cintra (dirs.), Enciclopedia Lingüística Hispánica, vol. I, Madrid, CSIC, pp. XXIX-LVII. 
Morala, José Ramón (2002): "De la complejidad interna del castellano en Castilla (y León)", en Carmen Saralegui y Manuel Casado (eds.), Pulchre, bene, recte. Estudios en homenaje al Prof. Fernando González Ollé, Pamplona, Eunsa, pp. 955-969.

Morala, José Ramón (2011): "La frontera histórica entre el asturleonés y el castellano", en Ramón de Andrés Díaz (coord.), Lengua, ciencia y fronteras, Oviedo, Trabe, pp. 89-119.

Morala, José Ramón (2017): "Lengua y vida cotidiana en la provincia de Zamora en el siglo XVII", Anuario del Instituto de Estudios Zamoranos Florián de Ocampo, XXXII, pp. 347-374.

Morf, Heinrich (1911): "Zur sprachlichen Gliederung Frankreichs", Abhandlungen der königlich preussischen Akademie der Wissenschaften, XXXVII, Berlin, Verlag der königl. Akad. Wiss.

Múgica, Serapio (1914-1917): "El obispado de Bayona con relación á los pueblos de Guipúzcoa adscritos á dicha diócesis", Revista Internacional de los Estudios Vascos, VIII, 2, pp. 185-229.

Nuño Álvarez, María del Pilar (1996): "Cantabria”, en Manuel Alvar (dir.), Manual de dialectología hispánica. El Español de España, Barcelona, Ariel, pp. 183-196.

Obispado de Salamanca (1991): Boletín Oficial del Obispado de Salamanca, V-VI.

Penny, Ralph (1978): "The northern transition area between Leonese and Castilian", Revue de linguistique romane, XLII, pp. 44-52, <http://doi.org/10.5169/seals-399655>.

Penny, Ralph (2003): "Continuum dialectal y fronteras estatales. El caso del leonés medieval", Orígenes de las lenguas romances en el Reino de León. Siglos IX-XII, I, León, Centro de Estudios e Investigación San Isidoro, pp. 565-578.

Reglero de la Fuente, Carlos (2016): "La diócesis de León en la Edad Media", en Francisco Javier Fernández Conde (coord.), Historia de las diócesis españolas: Iglesias de Oviedo y León, XVII, Madrid, Biblioteca de Autores Cristianos, pp. 575-651.

Rodríguez Castellano, Lorenzo (1954): 'Estado actual de la 'h' aspirada en la provincia de Santander", Archivum, IV, pp. 435-457.

Ronjat, Jules (1912): “Compte rendu de Morf, Heinrich (1911), etc.”, Revue des Langues Romanes, LV, pp. 418-422.

Sánchez Herrero, José (1978): Las diócesis del Reino de León. Siglos XIV y XV, León, Centro de Estudios e Investigación San Isidoro.

Sánchez Jiménez, Santiago U. (2016): "Dominios lingüísticos y variación en Castilla y León”, en Luis Díaz Viana y Dámaso Javier Vicente Blanco (eds.), El patrimonio cultural inmaterial de Castilla y León. Propuestas para un atlas etnográfico, Madrid, CSIC, pp. 47-81.

Sánchez Sevilla, Pedro (1928): "El habla de Cespedosa de Tormes", Revista de Filología Española, XV, pp. 131-172 y 244-282.

Seco Orosa, Ana (2001): "Determinación da fronteira lingüística entre o galego e o leonés nas provincias de León e Zamora", Revista de Filología Románica, XVIII, pp. 73-102.

Tallgren, Oiva Johannes (1913): "Un desideratum : L'atlas historique roman", Bulletin de Dialectologie Romane, V, pp. 1-20.

Trudgill, Peter (1992): "Dialect Contact, Dialectology and Sociolinguistics", en Kingsley Bolton y Helen Kwok (eds.), Sociolinguistics Today. International Perspectives, London/New York, Routledge, pp. 71-79.

Viejo Fernández, Xulio (2005): La formación histórica de la lengua asturiana, Oviedo, Trabe.

Zamora Vicente, Alonso (1960 [1989]): Dialectología española, $2^{\mathrm{a}}$ ed., Madrid, Gredos.

Zamora Vicente, Alonso (1982): "Regiones, con una lengua al fondo", Revista de Occidente, X-XI, pp. 23-32.

Zamora Vicente, Alonso (1987): "Situación actual del dialecto leonés", Revista de la Casa de León en Madrid, CCCXLV, pp. 16-27.

Fecha de recepción: 18 de febrero de 2019

Fecha de aceptación: 27 de marzo de 2019 